\title{
Article \\ No Evidence for Classic Thrombotic Microangiopathy in COVID-19
}

\author{
Tanja Falter ${ }^{1}$, Heidi Rossmann ${ }^{1}$ (D), Philipp Menge ${ }^{2}$, Jan Goetje ${ }^{2}$, Steffen Groenwoldt ${ }^{2}$, Arndt Weinmann ${ }^{2,3}$, \\ Visvakanth Sivanathan ${ }^{2}$, Andreas Schulz ${ }^{4}$, Niels A.W. Lemmermann 5 (D), Sven Danckwardt ${ }^{1,4}$, Karl J. Lackner ${ }^{1}$, \\ Peter R. Galle ${ }^{2}\left(\mathbb{D}\right.$, Inge Scharrer ${ }^{4}$, Bernhard Lämmle ${ }^{4,6,7} \mathbb{D}$ and Martin F. Sprinzl ${ }^{1,2,3, * \mathbb{D}}$
}

1 Institute of Clinical Chemistry and Laboratory medicine, University Medical Center of the Johannes Gutenberg University Mainz, 55131 Mainz, Germany; tanja.falter@unimedizin-mainz.de (T.F.); heidi.rossmann@unimedizin-mainz.de (H.R.); sven.danckwardt@unimedizin-mainz.de (S.D.); karl.lackner@unimedizin-mainz.de (K.J.L.)

2 Medical Department I, University Medical Center of the Johannes Gutenberg University Mainz, 55131 Mainz, Germany; pmenge@students.uni-mainz.de (P.M.); jan.goetje@gmx.de (J.G.); sgroenwo@students.uni-mainz.de (S.G.); arndt.weinmann@unimedizin-mainz.de (A.W.); visvakanth.sivanathan@unimedizin-mainz.de (V.S.); galle@uni-mainz.de (P.R.G.)

3 Clinical Registry Unit, University Medical Center of the Johannes Gutenberg University Mainz, 55131 Mainz, Germany

4 Center for Thrombosis and Hemostasis, University Medical Center of the Johannes Gutenberg University Mainz, 55131 Mainz, Germany; andreas.schulz@unimedizin-mainz.de (A.S.); inge.scharrer@unimedizin-mainz.de (I.S.); bernhard.laemmle@uni-mainz.de (B.L.)

5 Institute of Virology, University Medical Center of the Johannes Gutenberg University Mainz, 55131 Mainz, Germany; lemmermann@uni-mainz.de

6 Department of Hematology and Central Hematology Laboratory, Inselspital, Bern University Hospital, University of Bern, CH 3010 Bern, Switzerland

7 Haemostasis Research Unit, University College London, London WC1E 6BT, UK

Citation: Falter, T.; Rossmann, H.; Menge, P.; Goetje, J.; Groenwoldt, S.; Weinmann, A.; Sivanathan, V.; Schulz, A.; Lemmermann, N.A.W.; Danckwardt, S.; et al. No Evidence for Classic Thrombotic Microangiopathy in COVID-19. J. Clin. Med. 2021, 10, 671. https:// doi.org/10.3390/jcm10040671

Academic Editor: Simone Cesaro

Received: 22 December 2020

Accepted: 2 February 2021

Published: 9 February 2021

Publisher's Note: MDPI stays neutral with regard to jurisdictional claims in published maps and institutional affiliations.

* Correspondence: martin.sprinzl@unimedizin-mainz.de; Tel.: +49-6131-17-4406

Abstract: Background: Coronavirus disease-2019 (COVID-19) triggers systemic infection with involvement of the respiratory tract. There are some patients developing haemostatic abnormalities during their infection with a considerably increased risk of death. Materials and Methods: Patients $(n=85)$ with SARS-CoV-2 infection attending the University Medical Center, Mainz, from 3 March to 15 May 2020 were retrospectively included in this study. Data regarding demography, clinical features, treatment and laboratory parameters were analyzed. Twenty patients were excluded for assessment of disseminated intravascular coagulation (DIC) and thrombotic microangiopathy (TMA) due to lack of laboratory data. Results: COVID-19 patients $(n=65)$ were investigated, 19 with uncomplicated, 29 with complicated, and 17 with critical course; nine (13.8\%) died. Seven patients showed overt DIC according to the ISTH criteria. The fibrinogen levels dropped significantly in these patients, although not below $100 \mathrm{mg} / \mathrm{dl}$. Hallmarks of TMA, such as thrombocytopenia and microangiopathic haemolytic anaemia, were not detected in any of our COVID-19 patients. ADAMTS13 activity was mildly to moderately reduced in $4 / 22$ patients, all having strongly elevated procalcitonin levels. Conclusion: DIC occurred in 7/65 COVID-19 patients but fibrinogen and platelet consumption were compensated in almost all. ADAMTS13 assays excluded TTP and hallmarks of classic TMA were absent in all investigated patients. We hypothesize that the lacking erythrocyte fragmentation and only mild platelet consumption in severe COVID-19 are due to a microangiopathy predominantly localized to the alveolar microcirculation with a low blood pressure gradient.

Keywords: coronavirus disease; COVID-19; ADAMTS13; microangiopathy; disseminated intravascular coagulation

\section{Introduction}

Patient age, male sex and pre-existing comorbidities are the major determinants of $4.0 /)$. 
Acute Respiratory Syndrome-Coronavirus-2 (SARS-CoV-2) [1-3]. Some haemostasis parameters have been associated with poor outcome [4-6] and D-dimer values $>2 \mu \mathrm{g} / \mathrm{mL}$ predicted mortality among hospitalized COVID-19 patients [7]. These findings led to the recommendation to monitor haemostasis parameters in COVID-19 patients [8]. In line with laboratory surrogates of activated coagulation, COVID-19 is associated with increased rates of thromboembolic events in 15\% up to $69 \%$ [9-13]. Autopsy studies have confirmed that large vessel thromboembolic events and microthrombosis contribute to structural lung damage and respiratory failure [14-16]. Disseminated intravascular coagulation (DIC), as identified by a diagnostic DIC score, was found in $15 / 21(71.4 \%)$ patients with fatal outcome but only 1/162 (0.6\%) survivors [4]. DIC potentially evolves from endothelial activation or endothelial damage triggered by SARS-CoV-2 infection and subsequent consumption of plasmatic coagulation factors during COVID-19 [17-19]. DIC causes microvascular thrombosis, subsequent tissue malperfusion, and eventually drives multi organ failure. The clinical presentation of DIC during COVID-19 may have a similar appearance as thrombotic microangiopathies (TMAs) [20]. Classic TMAs, including thrombotic thrombocytopenic purpura (TTP), haemolytic uremic syndrome (HUS) and a series of other TMAs, describe an etiologically very heterogeneous group of conditions. TMAs are characterized by microvascular endothelial damage with increased release of von Willebrand factor (VWF) and widespread arteriolar and capillary thrombosis leading to the diagnostic hallmarks of consumptive thrombocytopenia and microangiopathic haemolytic anaemia (MAHA) with schistocytes in the blood smear [21,22].

A massive release of VWF from the endothelial cells, as it occurs in severe inflammatory states and systemic infections, can lead to a mild decrease of VWF-cleaving protease, a disintegrin and metalloprotease with thrombospondin type 1 motif 13 (ADAMTS13) [23]. Whether the resulting VWF/ADAMTS13 dysbalance contributes to the pathophysiology of certain TMAs in a similar way as in classic TTP characterized by a very severe deficiency of ADAMTS13 activity ( $<5-10 \%$ of normal) remains unclear.

We investigated clinical and laboratory patterns in this observational study to understand more about the underlying coagulopathy during COVID-19. In particular, we focused on clinical and laboratory features of DIC and classic TMAs.

\section{Materials and Methods}

Patients $(n=85)$ with confirmed SARS-CoV-2 infection who were seen at the University Medical Center, Mainz, Germany, between 3 March and 15 May 2020 were assessed in this observational study. Patient characteristics and laboratory findings were reviewed retrospectively through the electronic hospital information systems (i.s.h.med ${ }^{\circledR}$, SAP, Weinheim Germany, Nexus Swisslab, Berlin, Germany). The retrospective study was approved by German law [Landeskrankenhausgesetz §36 and §37] in accordance with the Declaration of Helsinki and by the local Ethics Committee of "Landesärztekammer Rheinland-Pfalz" (reference numbers: 2020-14988_2).

Severity of COVID-19 was classified by respiratory function into an uncomplicated, complicated, and critical clinical course. Patients with uncomplicated disease required neither monitoring nor oxygen supplementation, whereas patients affected by complicated COVID-19 were in need for oxygen supplementation and critically ill COVID-19 patients needed invasive ventilation. The categorization into the individual COVID-19 severity stages was done retrospectively based on the clinical course during hospitalization.

SARS-CoV-2 infection was confirmed by polymerase chain reaction (PCR) from respiratory samples, employing a PCR kit specific for SARS CoV-2 (Altona Diagnostics GmbH, Hamburg, Germany). All other laboratory assays were performed in the accredited (DINISO 15.189) Institute of Clinical Chemistry and Laboratory Medicine of the University Medical Center, Mainz. Renal injury was assessed based on Acute Kidney Injury Network (AKIN) criteria [24,25]. Presence of DIC was determined according to ISTH guidelines by the DIC score, incorporating platelet count, D-dimer, INR and fibrinogen level [26]. D-Dimer, derived fibrinogen and prothrombin time (PT/INR) were performed on ACL 
TOP 750 instruments (Instrumentation Laboratory Company, IL, Bedford, MA, USA) using IL reagents (HemosIL D-Dimer HS 500 and HemosIL RecombiPlasTin 2G) and following the manufacturer's instructions. ADAMTS13 activity was examined by the fluorescence resonance energy transfer system (FRETS-VWF73) method [27] modified according to Kremer-Hovinga et al. [28].

Statistical analyses employed SPSS version 22.0 (IBM GmbH, Ehningen, Germany). Descriptive statistics included frequency, mean, standard deviation, median, interquartile range (IQR), minimum and maximum. Explorative group comparisons were performed by $t$-test or Mann-Whitney-U-test for continuous variables and by Chi-squared test or Fisher's exact test for categorical variables, accordingly. $p$-values are two tailed, and $p$ values $<0.05$ were considered statistically significant.

Sixty-three/ 65 (97\%) COVID-19 patients were hospitalized and 20/65 (31\%) had to be treated in intensive care unit. COVID-19 patients were predominantly male $(63 \%)$ and had a median age of 69 (IQR 57-79, range 22-86) years. Older adults (age $>65$ years) accounted for $37 / 65(57 \%)$. The most common underlying comorbidities were arterial hypertension, cardiovascular disease and diabetes mellitus. Obesity $\left(\mathrm{BMI} \geq 30 \mathrm{~kg} / \mathrm{m}^{2}\right)$ was observed in 23/62 (37\%) and a history of venous thromboembolic events before COVID-19 in 4/65 $(6 \%)$. The clinical course of COVID-19 was uncomplicated in 19 (29\%), complicated in 29 $(45 \%)$ and critical in $17(26 \%)$. The overall mortality rate was 14\% (9/65), reaching 35\% $(6 / 17)$ in critical COVID-19. Invasive ventilation of 17 critically ill patients was performed over a period of 21 (median, IQR 7-30) days. Prophylactic or therapeutic anticoagulation was used in 43/46 (94\%) patients with complicated or critical COVID-19 manifestation and in $14 / 19(74 \%)$ of the uncomplicated cases (Table 1$)$.

\section{Results}

\subsection{Patient Characteristics}

A total of 85 patients with proven SARS-CoV-2 infection were seen between 3 March and 15 May 2020. For the assessment of haemostatic alterations, 20 patients were excluded due to insufficient laboratory data (Table 1 and Table S1.1).

Table 1. Characteristics of 65 patients with COVID-19 and analyzed for haemostatic abnormalities.

\begin{tabular}{|c|c|c|c|c|c|}
\hline Characteristics & Total & $\begin{array}{l}\text { Uncomplicated } \\
\text { COVID-19 }\end{array}$ & $\begin{array}{c}\text { Complicated } \\
\text { COVID-19 }\end{array}$ & $\begin{array}{c}\text { Critical } \\
\text { COVID-19 }\end{array}$ & $\operatorname{DIC}^{\mathrm{a}}$ \\
\hline $\begin{array}{c}\text { Number } \\
\text { Age (years) (IQR) }\end{array}$ & $\begin{array}{c}65 \\
69(57-79)\end{array}$ & $\begin{array}{c}19 \\
64(39-79)\end{array}$ & $\begin{array}{c}29 \\
74(60-81)\end{array}$ & $\begin{array}{c}17 \\
66(53-73)\end{array}$ & $\begin{array}{c}7 \\
76(55-80)\end{array}$ \\
\hline Sex (male/female) & $\begin{array}{c}41 / 24 \\
(63.1 / 36.9 \%)\end{array}$ & $\begin{array}{c}10 / 9 \\
(52.6 / 47.4 \%)\end{array}$ & $\begin{array}{c}17 / 12 \\
(58.6 / 41.4 \%)\end{array}$ & $\begin{array}{c}14 / 3 \\
(82.4 / 17.6 \%)\end{array}$ & $7 / 0(100 / 0.0 \%)$ \\
\hline $\mathrm{BMI}\left(\mathrm{kg} / \mathrm{m}^{2}\right)(\mathrm{IQR})^{\mathrm{b}}$ & $27.2(24.2-33.6)$ & $26.7(22.5-32.6)$ & $29.4(24.4-33.6)$ & $27.0(25.7-33.5)$ & $27.0(24.7-29.4)$ \\
\hline \multicolumn{6}{|c|}{ Preexisting comorbidities } \\
\hline Arterial Hypertension & $38(58.5 \%)$ & $9(47.4 \%)$ & $9(31 \%)$ & $10(58.8 \%)$ & $6(85.6 \%)$ \\
\hline Diabetes mellitus & $14(21.5 \%)$ & $1(5.3 \%)$ & $8(27.6 \%)$ & $5(29.4 \%)$ & $2(28.6 \%)$ \\
\hline Obesity $\left(\mathrm{BMI} \geq 30 \mathrm{~kg} / \mathrm{m}^{2}\right)^{\mathrm{b}}$ & $23 / 62(37.1 \%)$ & $5 / 16(31.1 \%)$ & $13 / 29(44.8 \%)$ & $5 / 17(29.4 \%)$ & $1 / 7(14.3 \%)$ \\
\hline Chronic respiratory disease & $11(16.9 \%)$ & $2(10.5 \%)$ & $6(20.7 \%)$ & $3(17.6 \%)$ & $1(14.3 \%)$ \\
\hline Cardiovascular disease & $17(26.2 \%)$ & $5(26.3 \%)$ & $8(27.6 \%)$ & $4(23.5 \%)$ & $3(42.9 \%)$ \\
\hline Cerebrovascular disease & $11(16.9 \%)$ & $2(10.5 \%)$ & $3(10.3 \%)$ & $6(35.3 \%)$ & $1(14.3 \%)$ \\
\hline Terminal renal insufficiency & $2(3.1 \%)$ & $1(5.3 \%)$ & $1(3.4 \%)$ & $0(0.0 \%)$ & $0(0.0 \%)$ \\
\hline $\begin{array}{l}\text { Venous thromboembolic } \\
\text { history }\end{array}$ & $4(6.2 \%)$ & $0(0.0 \%)$ & $1(3.4 \%)$ & $3(17.6 \%)$ & $1(14.3 \%)$ \\
\hline Pulmonary Embolism & $1(1.5 \%)$ & $0(0.0 \%)$ & $1(3.4 \%)$ & $0(0.0 \%)$ & $0(0.0 \%)$ \\
\hline Deep vein thrombosis & $4(6.2 \%)$ & $0(0.0 \%)$ & $1(3.4 \%)$ & $3(17.6 \%)$ & $1(14.3 \%)$ \\
\hline \multicolumn{6}{|c|}{ Preexisting anticoagulation } \\
\hline \multirow{3}{*}{$\begin{array}{c}\text { DOAC } \\
\text { Vitamin K antagonist } \\
\text { Platelet aggregation } \\
\text { inhibitors }\end{array}$} & $1(1.5 \%)$ & $0(0.0 \%)$ & $1(3.4 \%)$ & $0(0.0 \%)$ & $1(14.3 \%)$ \\
\hline & $1(1.5 \%)$ & $0(0.0 \%)$ & $0(0.0 \%)$ & $1(5.9 \%)$ & $0(0.0 \%)$ \\
\hline & $19(29.2 \%)$ & $8(42.1 \%)$ & $7(24.1 \%)$ & $4(23.5 \%)$ & $0(0.0 \%)$ \\
\hline
\end{tabular}


Table 1. Cont.

\begin{tabular}{|c|c|c|c|c|c|}
\hline Characteristics & Total & $\begin{array}{l}\text { Uncomplicated } \\
\text { COVID-19 }\end{array}$ & $\begin{array}{c}\text { Complicated } \\
\text { COVID-19 }\end{array}$ & $\begin{array}{c}\text { Critical } \\
\text { COVID-19 }\end{array}$ & $\mathrm{DIC}^{\mathrm{a}}$ \\
\hline \multicolumn{6}{|c|}{ Clinical complications during COVID-19 infection } \\
\hline Renal failure & $18(27.7 \%)$ & $0(0.0 \%)$ & $5(17.2 \%)$ & $13(76.5 \%)$ & $4(57.1 \%)$ \\
\hline AKIN 1 & $3(4.6 \%)$ & $0(0.0 \%)$ & $2(6.9 \%)$ & $1(5.9 \%)$ & $0(0.0 \%)$ \\
\hline AKIN 3 & $15(23.1 \%)$ & $0(0.0 \%)$ & $3(10.3 \%)$ & $12(70.6 \%)$ & $4(57.1 \%)$ \\
\hline Thromboembolic events & $4(6.2 \%)$ & $1(5.3 \%)$ & $0(0.0 \%)$ & $3(17.6 \%)$ & $1(14.3 \%)$ \\
\hline Acute coronary syndrome & $3(4.6 \%)$ & $0(0.0 \%)$ & $2(6.9 \%)$ & $1(5.9 \%)$ & $1(14.3 \%)$ \\
\hline Myocarditis & $2(3.1 \%)$ & $2(3.1 \%)$ & $0(0.0 \%)$ & $0(0.0 \%)$ & $0(0.0 \%)$ \\
\hline \multicolumn{6}{|c|}{ Medical care during COVID-19 infection } \\
\hline Hospitalized & $63(96.9 \%)$ & $17(89.5 \%)$ & $29(100 \%)$ & $17(100 \%)$ & $7(100 \%)$ \\
\hline Intensive care & $20(30.8 \%)$ & $0(0.0 \%)$ & $3(10.3 \%)$ & $17(100 \%)$ & $4(57.1 \%)$ \\
\hline Oxygen supplementation & $46(70.8 \%)$ & - & $29(100 \%)$ & $17(100 \%)$ & $7(100 \%)$ \\
\hline Invasive ventilation & $17(26.2 \%)$ & - & - & $17(100 \%)$ & $4(57.1 \%)$ \\
\hline Renal replacement therapy & $10(15.4 \%)$ & $0(0.0 \%)$ & $0(0.0 \%)$ & $10(58.8 \%)$ & $3(42.9 \%)$ \\
\hline \multicolumn{6}{|c|}{ Anticoagulation during COVID-19 infection } \\
\hline None & $7(10.8 \%)$ & $5(26.3 \%)$ & $2(6.9 \%)$ & $0(0.0 \%)$ & $1(14.3 \%)$ \\
\hline Prophylactic dose LMWH & $43(66.2 \%)$ & $13(68.4 \%)$ & $25(86.2 \%)$ & $5(29.4 \%)$ & $2(28.6 \%)$ \\
\hline Therapeutic dose LMWH & $14(21.5 \%)$ & $1(5.3 \%)$ & $1(3.4 \%)$ & $12(70.6 \%)$ & $3(42.9 \%)$ \\
\hline DOAC & $1(1.5 \%)$ & $0(0.0 \%)$ & $1(3.4 \%)$ & $0(0.0 \%)$ & $1(14.3 \%)$ \\
\hline \multicolumn{6}{|c|}{ Clinical outcome of COVID-19 infection } \\
\hline Uncomplicated & $19(29.2 \%)$ & $19(100 \%)$ & - & - & $0(0.0 \%)$ \\
\hline Complicated & $29(44.6 \%)$ & - & $29(100 \%)$ & - & $3(42.9 \%)$ \\
\hline Critical & $17(26.2 \%)$ & - & - & $17(100 \%)$ & $4(57.1 \%)$ \\
\hline Deceased & $9(13.8 \%)$ & $0(0 \%)$ & $3(10.3 \%)$ & $6(35.3 \%)$ & $3(42.9 \%)$ \\
\hline
\end{tabular}

Patient characteristics are presented as median (interquartile range) or number (\%). Explorative comparisons of patient subgroups and corresponding $p$-values are provided in supplemental Table S1.2. AKIN, AKIN Classification for Acute Kidney Injury; BMI, body mass index; COVID-19, coronavirus disease-2019; DOAC, direct oral anticoagulants; DIC, disseminated intravascular coagulation; IQR, interquartile range; LMWH, low molecular weight heparin. ${ }^{\text {a }}$ Patients with DIC are a subset of patients with complicated and critical COVID-19. ${ }^{\mathrm{b}} \mathrm{BMI}$ and obesity could only be determined in 62 of 65 patients due to missing anthropometric data.

\subsection{COVID-19-Associated Laboratory Parameters and Organ Damage}

Elevated creatinine values were observed in 38/64 (59\%) throughout the course of COVID-19 (Table 2 and Table S2.1 and Figure S1). According to the Classification for Acute Kidney Injury (AKIN) patients with COVID-19 developed a new onset of renal injury (AKIN 1) and renal failure (AKIN 3) in 33/65 (5\%) and 15/65 (23\%), respectively (Table 1). Renal replacement therapy was eventually initiated in 10/65 (15.4\%) patients (Table 1$)$.

Elevated troponin I ( $>24 \mathrm{pg} / \mathrm{mL})$ indicative of myocardial injury was observed in 27/61 (44\%) of all COVID-19 patients (Table 2 and Table S2.1 and Figure S1). In patients with myocardial injury, 9/27 (33\%) had arrhythmic events, $2 / 27$ had a myocarditis and $3 / 27(11 \%)$ were diagnosed with acute coronary syndrome (Table 1$)$.

Significant increases ( $>5$ times the upper limit of normal) in AST and ALT were observed in 17/63 (27\%) and 9/64 (14\%), respectively. Impaired liver function as indicated by hyperbilirubinemia (total bilirubin $>1.2 \mathrm{mg} / \mathrm{dL}$ ) and pronounced hypoalbuminemia (serum albumin $<28 \mathrm{~g} / \mathrm{L}$ ) occurred in 17/64 (27\%) and 31/58 (53\%), respectively (Table 2 and Table S2.1 and Figure S1).

Table 2. Laboratory analyses of 65 patients with COVID-19 analyzed for haemostatic abnormalities.

\begin{tabular}{|c|c|c|c|c|c|c|c|c|c|c|}
\hline \multirow{2}{*}{$\begin{array}{c}\text { Parameter } \\
\begin{array}{c}\text { Number of } \\
\text { Patients }\end{array}\end{array}$} & \multicolumn{2}{|l|}{ Total } & \multicolumn{2}{|c|}{$\begin{array}{l}\text { Uncomplicated } \\
\text { COVID-19 }\end{array}$} & \multicolumn{2}{|c|}{$\begin{array}{c}\text { Complicated } \\
\text { COVID-19 }\end{array}$} & \multicolumn{2}{|c|}{$\begin{array}{c}\text { Critical } \\
\text { COVID-19 }\end{array}$} & \multicolumn{2}{|l|}{ DIC $^{a}$} \\
\hline & 65 & $\#$ & 19 & $\#$ & 29 & \# & 17 & $\#$ & 7 & \# \\
\hline $\mathrm{LDH}^{\max }(\mathrm{U} / \mathrm{L})$ & $507(381-705)$ & 63 & $421(345-476)$ & 17 & $495(367-593)$ & 29 & 705 (629-786) & 17 & $\begin{array}{c}832 \\
(641-1849) \\
\end{array}$ & 7 \\
\hline $\mathrm{AST}^{\max }(\mathrm{U} / \mathrm{L})$ & $76(46-187)$ & 63 & 49 (35-76) & 19 & 69 (47-110) & 28 & $206(103-394)$ & 16 & $188(93-229)$ & 6 \\
\hline
\end{tabular}


Table 2. Cont.

\begin{tabular}{|c|c|c|c|c|c|c|c|c|c|c|}
\hline \multirow{2}{*}{$\begin{array}{c}\text { Parameter } \\
\begin{array}{c}\text { Number of } \\
\text { Patients }\end{array}\end{array}$} & \multicolumn{2}{|l|}{ Total } & \multicolumn{2}{|c|}{$\begin{array}{l}\text { Uncomplicated } \\
\text { COVID-19 }\end{array}$} & \multicolumn{2}{|c|}{$\begin{array}{l}\text { Complicated } \\
\text { COVID-19 }\end{array}$} & \multicolumn{2}{|l|}{$\begin{array}{c}\text { Critical } \\
\text { COVID-19 }\end{array}$} & \multicolumn{2}{|l|}{$\operatorname{DIC}^{\mathrm{a}}$} \\
\hline & 65 & $\#$ & 19 & $\#$ & 29 & $\#$ & 17 & \# & 7 & \# \\
\hline $\operatorname{ALT}^{\max }(\mathrm{U} / \mathrm{L})$ & $51(33-1429)$ & 64 & $41(31-66)$ & 18 & $43(28-69)$ & 29 & $156(75-395)$ & 17 & $111(22-927)$ & 7 \\
\hline $\mathrm{GGT}^{\max }(\mathrm{U} / \mathrm{L})$ & $87(43-180)$ & 63 & $58(39-140)$ & 18 & $66(3-113)$ & 28 & $526(145-988)$ & 17 & 149 (44-988) & 7 \\
\hline $\begin{array}{l}\text { Total bilirubin } \\
\text { (mg/dl) }\end{array}$ & $0.8(0.6-1.4)$ & 64 & $0.7(0.5-0.8)$ & 18 & $0.7(0.6-0.9)$ & 29 & $2.5(1.4-3.3)$ & 17 & $2.8(1.5-7.0)$ & 7 \\
\hline $\operatorname{Albumin}^{\min }(\mathrm{g} / \mathrm{L})$ & $26(20-32)$ & 58 & $30(25-35)$ & 17 & $28(24-33)$ & 28 & $12(11-16)$ & 13 & $16(10-22)$ & 7 \\
\hline $\mathrm{CK}^{\max }(\mathrm{U} / \mathrm{L})$ & $301(97-798)$ & 62 & $161(76-303)$ & 19 & $226(77-490)$ & 26 & $\begin{array}{c}1359 \\
(768-2616)\end{array}$ & 17 & $\begin{array}{c}480 \\
(154-2357)\end{array}$ & 7 \\
\hline $\mathrm{TNI}^{\mathrm{max}}(\mathrm{pg} / \mathrm{mL})$ & $\begin{array}{c}18.7 \\
(10.6-89.3)\end{array}$ & 61 & $\begin{array}{c}16.8 \\
(5.8-56.5)\end{array}$ & 19 & $\begin{array}{c}15.8 \\
(6.6-21.2)\end{array}$ & 25 & $\begin{array}{c}89.3 \\
(35.3-421)\end{array}$ & 17 & $\begin{array}{c}70.7 \\
(15.8-421)\end{array}$ & 7 \\
\hline $\begin{array}{l}\text { Creatinine }{ }^{\max } \\
(\mathrm{mg} / \mathrm{dL})\end{array}$ & $1.2(0.93-2.1)$ & 64 & $\begin{array}{c}0.96 \\
(0.74-1.18) \\
\end{array}$ & 19 & $\begin{array}{c}1.21 \\
(0.90-1.64) \\
\end{array}$ & 28 & $\begin{array}{c}2.16 \\
(1.64-3.33) \\
\end{array}$ & 17 & $\begin{array}{c}2.16 \\
(1.56-4.35) \\
\end{array}$ & 7 \\
\hline $\begin{array}{l}\text { Hemoglobin }^{\min } \\
(\mathrm{g} / \mathrm{dL})\end{array}$ & $\begin{array}{c}10.3 \\
(8.0-12.5)\end{array}$ & 65 & $\begin{array}{c}11.8 \\
(7.6-13.6)\end{array}$ & 19 & $\begin{array}{c}11.5 \\
(10.3-12.6)\end{array}$ & 29 & $7.4(7.0-8.4)$ & 17 & $8.0(6.7-11.4)$ & 7 \\
\hline $\begin{array}{c}\text { Platelet } \\
\text { count }^{\text {min } / \mathrm{nL}}\end{array}$ & 178 (134-227) & 65 & $184(134-233)$ & 19 & $185(142-233)$ & 29 & 170 (133-183) & 17 & $71(49-160)$ & 7 \\
\hline $\begin{array}{c}\text { Absolute } \\
\text { leukocytes }^{\max } / \mathrm{nL}\end{array}$ & $7.6(5.4-9.7)$ & 62 & $6.72(4.6-8.3)$ & 18 & $7.0(5.6-9.5)$ & 29 & $9.2(7.3-11.4)$ & 15 & $8.0(6.0-17.3)$ & 7 \\
\hline $\begin{array}{c}\text { Absolute } \\
\text { neutrophiles }^{\max } / \mathrm{nL}\end{array}$ & $5.7(3.5-8.7)$ & 62 & $4.5(3.0-6.9)$ & 18 & $5.4(3.9-7.8)$ & 29 & $8.1(5.1-10.0)$ & 15 & $5.8(4.6-13.8)$ & 7 \\
\hline $\begin{array}{c}\text { Absolute } \\
\text { lymphocytes }\end{array}$ & $0.7(0.5-1.0)$ & 62 & $0.9(0.6-1.4)$ & 18 & $0.6(0.5-1.0)$ & 29 & $0.6(0.5-0.8)$ & 15 & $0.6(0.4-0.9)$ & 7 \\
\hline $\mathrm{CRP}^{\max }(\mathrm{mg} / \mathrm{lL})$ & $172(83-285)$ & 65 & $118(39-176)$ & 19 & $121(48-184)$ & 29 & $385(348-413)$ & 17 & $348(176-458)$ & 7 \\
\hline $\mathrm{PCT}^{\max }(\mathrm{ng} / \mathrm{mL})$ & $\begin{array}{c}0.18 \\
(0.05-1.20)\end{array}$ & 65 & $\begin{array}{c}0.05 \\
(0.02-0.24)\end{array}$ & 19 & $\begin{array}{c}0.08 \\
(0.05-0.24)\end{array}$ & 29 & $\begin{array}{c}4.30 \\
(1.0-11.0)\end{array}$ & 17 & $\begin{array}{c}\text { 7.00.(0.77- } \\
17.0)\end{array}$ & 7 \\
\hline $\mathrm{INR}^{\max }$ & $1.2(1.1-1.5)$ & 65 & $1.2(1.1-1.3)$ & 19 & $1.2(1.1-1.3)$ & 29 & $1.6(1.5-2.2)$ & 17 & $2.6(1.5-3.6)$ & 7 \\
\hline $\begin{array}{l}\text { Fibrinogen }{ }^{\max } \\
(\mathrm{mg} / \mathrm{dL})\end{array}$ & $586(476-759)$ & 58 & $518(479-582)$ & 16 & $495(442-610)$ & 25 & 855 (730-897) & 17 & $586(517-890)$ & 7 \\
\hline $\begin{array}{l}\text { Fibrinogen } \\
\quad(\mathrm{mg} / \mathrm{dL})\end{array}$ & $465(358-531)$ & 58 & $428(287-505)$ & 16 & $474(389-561)$ & 25 & $469(364-531)$ & 17 & $371(284-453)$ & 7 \\
\hline $\begin{array}{l}\text { D-dimer } \\
(\mathrm{mg} / \mathrm{L})\end{array}$ & $\begin{array}{c}1.67 \\
(0.86-5.08)\end{array}$ & 65 & $\begin{array}{c}1.12 \\
(0.51-1.93)\end{array}$ & 19 & $\begin{array}{c}1.14 \\
(0.69-2.27)\end{array}$ & 29 & $\begin{array}{c}6.16 \\
(4.36-17.23)\end{array}$ & 17 & $\begin{array}{c}7.07 \\
(2.24-40.24)\end{array}$ & 7 \\
\hline
\end{tabular}

Maximum (max) or minimum (min) laboratory values of each patient during the follow up until 15 May 2020 presented as medians (interquartile ranges). Explorative comparisons of patient subgroups and corresponding $p$-values are provided in Supplementary Table S2.2. CK, creatine kinase; COVID-19, coronavirus disease-2019; CRP, C-reactive protein; DIC, disseminated intravascular coagulation; AST, aspartate-aminotransferase, ALT, alanine-aminotransferase; GGT, gamma-glutamyltransferase; INR, international normalized ratio; LDH, lactate dehydrogenase; PCT, procalcitonin; TNI, troponin I. \# Number of total patients and patients with uncomplicated, complicated, and critical COVID-19 course, and with DIC for whom laboratory values were available. ${ }^{\text {a }}$ Patients with DIC are a subset of patients with complicated and critical COVID-19.

\subsection{COVID-19 Associated Haemostatic Alterations}

3.3.1. Thromboembolic Events during COVID-19

Among our COVID-19 patients, acute new-onset thromboembolic (TE) events were observed in 4/65 (6\%) (Table 1). These TE events predominantly affected patients with critical COVID-19 $(3 / 17,18 \%)$ and only $1 / 19$ patients (5\%) with uncomplicated COVID-19. The TE events during critical COVID-19 included two patients with venous thrombosis associated with central vein catheters and one with acute arterial mesenterial infarction. The patient with uncomplicated COVID-19 developed a segmental pulmonary embolism. Twenty-seven patients had cardiac troponin I elevation (Table S2.1) and three of them required interventional coronary angioplasty for acute coronary syndrome (Table 1).

As shown in Table 1,57/65 patients (88\%) were treated with prophylactic or therapeutic doses of LMW-heparin from the time of hospitalization. In particular, all patients who developed thromboembolic events during COVID-19 received therapeutic doses of 
LMW-heparin. One patient had been under rivaroxaban because of deep vein thrombosis and lung embolism that had occurred prior to COVID-19. No major bleeding event was observed during hospitalization and heparin-induced thrombocytopenia did not occur.

\subsubsection{D-Dimers, Fibrinogen, INR, Platelet Count}

Elevation of INR and D-dimers along with COVID-19 severity was evident (Table 2 and Table S2.1 and Figure 1). Consequently, the highest median INR (1.6, IQR 1.5-2.2, range 1.4-10.6) and highest median D-dimer $(6.16 \mathrm{mg} / \mathrm{L}$, IQR $4.36-17.23 \mathrm{mg} / \mathrm{L}$, range $1.22-43.72 \mathrm{mg} / \mathrm{L}$ ) was reached among critically ill COVID-19 patients. D-dimer concentrations $>2 \mathrm{mg} / \mathrm{L}$, which had been associated with adverse outcome [7], were observed in $25 / 65(40 \%)$ of the entire cohort and in 13/17 (81\%) patients with critical COVID-19 (Table 2). In contrast, platelet counts and fibrinogen levels did not significantly differ between patient subgroups of increasing COVID-19 severity (Table 2 and Table S2.1 and Figure 1).
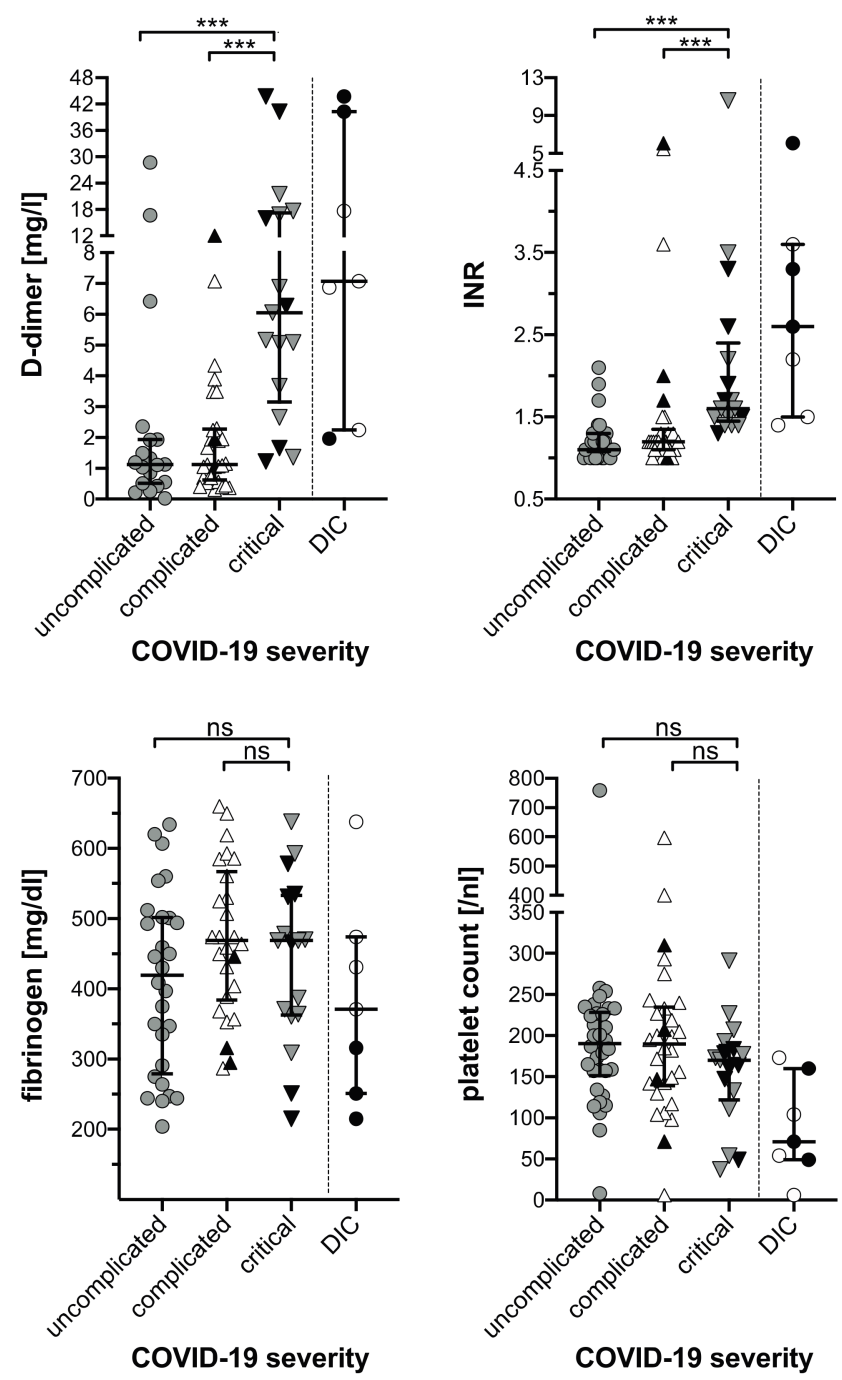

Figure 1. Haemostasis parameters of COVID-19 patients. The highest values for D-dimer and INR as well as the lowest values for fibrinogen and platelet count are plotted against the severity of COVID-19 disease and the occurrence of DIC as indicated. Black symbols represent laboratory values of deceased COVID-19 patients. Median and interquartile range are provided. Comparisons between subgroups were based on Mann-Whitney U Test (ns, not significant; ${ }^{* * *} p<0.001$ ). COVID-19, coronavirus disease-19; DIC, disseminated intravascular coagulation; INR, international normalized ratio. 
Fibrinogen levels in COVID-19 patients were elevated in 49/58 (84\%) at baseline (median 531, IQR 465-660, range 275-933 mg/dL). Particularly all patients (17/17) with critical COVID-19 presented with elevated baseline fibrinogen levels (median 714, IQR 613-855, range 466-933 mg/dL). During the course of COVID-19 maximum fibrinogen concentrations were above normal in the entire COVID-19 cohort (Table 2 and Table S2.1) and remained elevated for several days in most patients

\subsubsection{Patients with DIC}

Overt disseminated intravascular coagulation (DIC), as defined by a DIC Score $\geq 5$ points (26), was present in 7/65 (11\%) patients (Table 3 and Table S3, Figure 2).

Table 3. Constituting subscores of the DIC score in the seven patients with overt DIC.

\begin{tabular}{|c|c|c|c|}
\hline \multicolumn{2}{|r|}{ Parameters of DIC Score } & Points & Number of Patients (\%) \\
\hline \multicolumn{3}{|c|}{ Meeting the ISTH Criteria of Overt DIC (total points $\geq 5$ ) ${ }^{a}$} & $7(100)$ \\
\hline \multirow{3}{*}{ Platelets } & $>100 / \mathrm{nL}$ & 0 & $3(42.8)$ \\
\hline & $50-100 / \mathrm{nL}$ & 1 & $2(28.6)$ \\
\hline & $<50 / \mathrm{nL}$ & 2 & $2(28.6)$ \\
\hline \multirow{3}{*}{ D-dimer } & $\operatorname{normal}(<0.5 \mathrm{mg} / \mathrm{L})$ & 0 & $0(0)$ \\
\hline & moderately elevated $(0.5-2.0 \mathrm{mg} / \mathrm{L})$ & 2 & $1(14.3)$ \\
\hline & extremely elevated (>2.0 mg/L) & 3 & $6(85.7)$ \\
\hline \multirow{3}{*}{ INR } & $<1.25$ & 0 & $0(0)$ \\
\hline & $1.25-1.7$ & 1 & $2(28.6)$ \\
\hline & $>1.7$ & 2 & $5(71.4)$ \\
\hline \multirow{2}{*}{ Fibrinogen } & $\geq 100 \mathrm{mg} / \mathrm{dL}$ & 0 & $7(100)$ \\
\hline & $<100 \mathrm{mg} / \mathrm{dL}$ & 1 & $0(0)$ \\
\hline
\end{tabular}

The dynamics of laboratory values included into the DIC score are shown for the seven patients who developed DIC over the course of hospitalisation (Figure 2). The DIC score became positive after a median of 21 (range 6.5-40) days post hospital admission. DIC diagnosis was mainly based on moderately $(0.5-2.0 \mathrm{mg} / \mathrm{L})$ or extremely $(>2.0 \mathrm{mg} / \mathrm{L})$ elevated D-dimers and an INR above 1.7. Patients with positive DIC score included only four patients (Pat.ID 24/ 50/ 74/ 79) with thrombocytopenia (platelets $<100 / \mathrm{nL}$ ) (Figure 2). Fibrinogen levels were elevated in all seven patients at hospitalisation, followed by a decrease in fibrinogen levels over time (Figure 2). However, fibrinogen remained $\geq 100 \mathrm{mg} / \mathrm{dl}$ in all seven patients meeting the criteria for DIC (Table 3 and Figure 2). DIC was only diagnosed in male patients with complicated or critical COVID-19, three patients died (Table 1 and Figure 2). DIC patients had more pronounced LDH, total bilirubin and creatinine elevations as compared to the non-DIC group (Table 2 and Table S2.2). Two patients received low molecular weight heparin in prophylactic doses, three patients in therapeutic doses and one patient continued rivaroxaban introduced prior to COVID-19 infection (Table 1). 

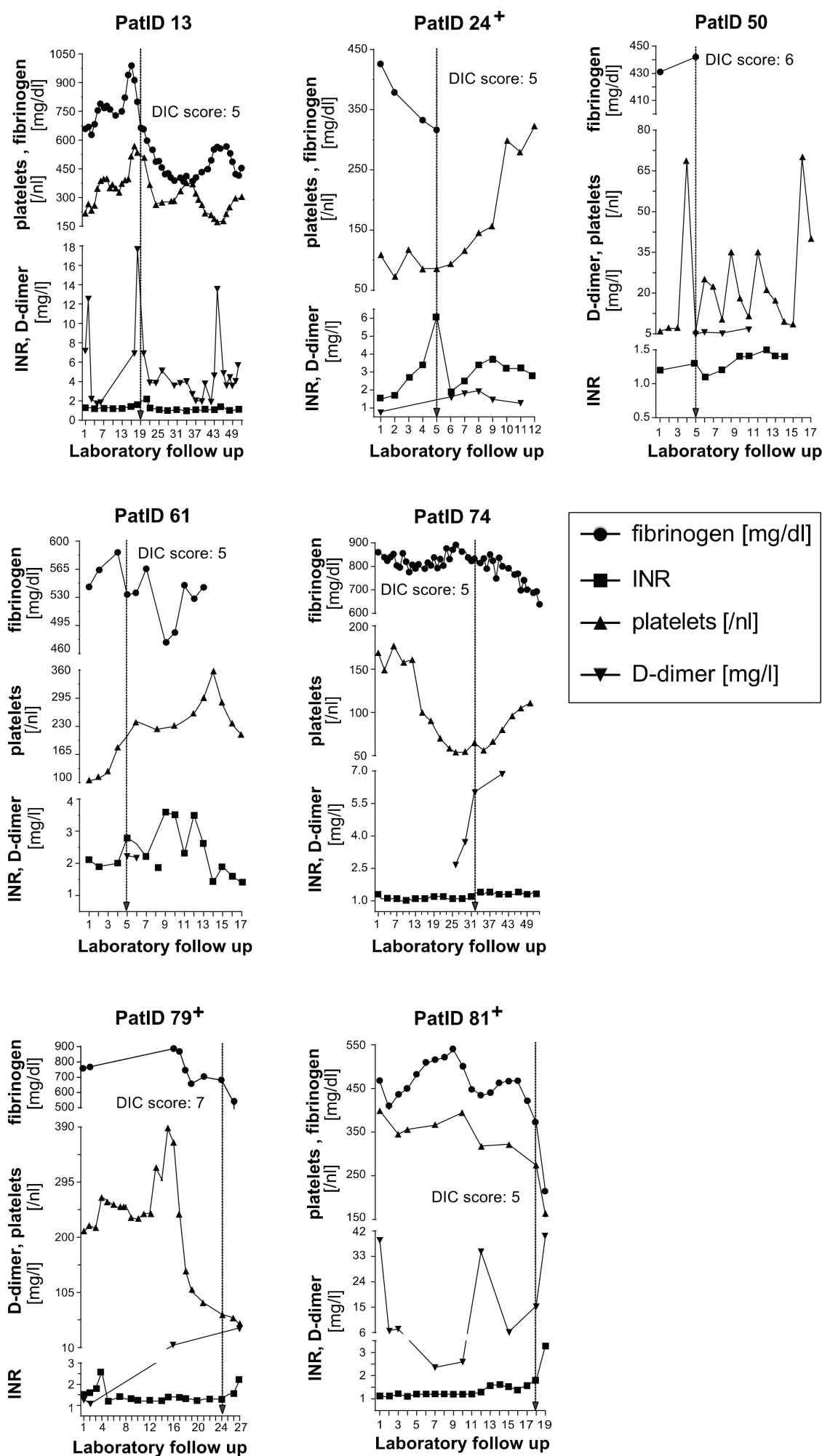

Figure 2. Time course of fibrinogen, INR, platelet count and D-dimer values in seven patients who developed DIC during COVID-19. The engraved arrow indicates the time of DIC manifestation as defined by the corresponding DIC score. Three patients with DIC died as indicated (+). DIC, disseminated intravascular coagulation; INR, international normalized ratio; PatID, patient identification number. 


\subsubsection{Markers of Endothelial Damage and Thrombotic Microangiopathy}

Some authors reported that severe COVID-19 may cause thrombotic microangiopathy (TMA) [20,29-31]. Therefore, we examined patients for microangiopathic haemolytic anaemia (MAHA) and consumptive thrombocytopenia as hallmarks of classic TMA [21].

Anaemia using a haemoglobin cut-off for males $(<13.5 \mathrm{~g} / \mathrm{dL})$ and females $(<12.0 \mathrm{~g} / \mathrm{dL})$ was observed in 52/65 (80\%) of our COVID-19 patients (Table S2.1). Haemoglobin reduction paralleled the severity of COVID-19, leading to anaemia in 23/29 (79\%) patients with complicated COVID-19 and in 17/17 (100\%) patients with critical COVID-19. Despite elevated LDH levels in 60/63 (95\%) patients (Table S2.1) being compatible with haemolysis, available haptoglobin values from 22 patients across all COVID-19 stages were all normal or elevated (Table 4). In addition, schistocytes were either absent in the peripheral blood smear of 20 investigated patients or only minimally elevated (i.e., $5 \%$ and $9 \%$ ) in two. Based on these findings MAHA with intravascular haemolysis was not observed in this cohort (Table 4).

Platelet counts were $<150 / \mathrm{nL}$ in $22 / 65(34 \%)$ without clear relation to disease severity (Table S2.1). However, thrombocytopenia was generally mild (platelets $100-<150 / \mathrm{nL}$ ) in $15 / 65(23 \%)$ or moderate (platelets $50-<100 / \mathrm{nL}$ ) in $4 / 65(6 \%)$ (Table S2.1). Severe thrombocytopenia (platelets $<50 / \mathrm{nL}$ ) was found in only three $(5 \%)$ patients of whom one had received cytotoxic chemotherapy.

Finally, ADAMTS13 was mostly in the normal range and only $4 / 22$ tested showed reduced ADAMTS13 activity values $(<50 \%)$ with a minimum ADAMTS13 activity of $17.8 \%$ (Table 4). These mild or moderately decreased ADAMTS13 activity values excluded thrombotic thrombocytopenic purpura in any patient. Most prominent finding in these 22 patients, comprehensively tested for the presence of TMA, were the elevated VWF activity (median 329\%, IQR 195 - >390\%) and antigen (median 232\%, IQR 219-498\%) levels (Table 4). The VWF antigen/ ADAMTS13 activity ratio was elevated in 21/21 (100\%) patients tested (median 3.4, IQR 2.6-7.7, range 2.1-33.4) (Table 4).

It is remarkable that in the four patients with mild to moderately reduced ADAMTS13 activity (18-48\%) by far the highest procalcitonin (PCT) values were found. Bacterial coinfections were confirmed in two cases by Escherichia coli and Staph epidermidis isolates from the lower respiratory system and blood stream, respectively.

In sum, there were no diagnostic clues for classic TMA (lacking schistocytes, normal or elevated haptoglobin levels, no severe thrombocytopenia) in any of our patients whereas the consistently high VWF levels were compatible with an endothelial activation and/or damage. 


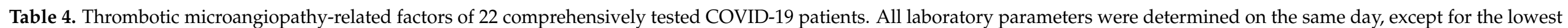
platelet count.

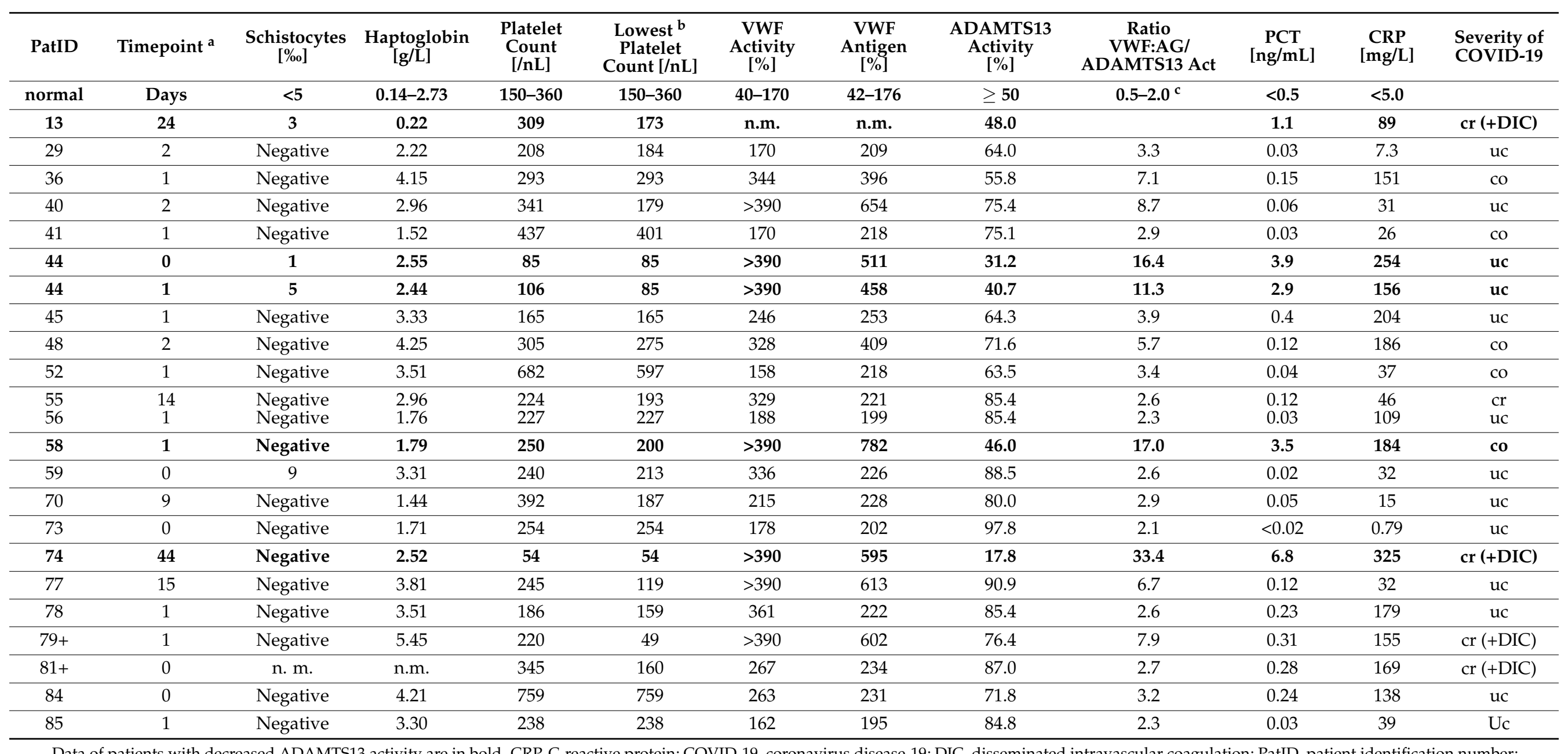

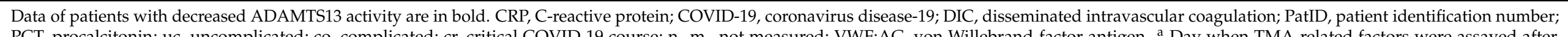

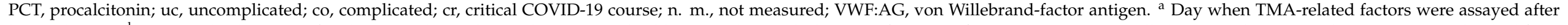

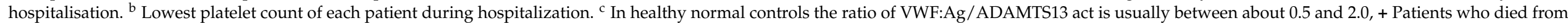
COVID-19 during hospitalization. 


\section{Discussion}

We present here our single-centre cohort of all consecutive, retrospectively included patients diagnosed with COVID-19 at the University Medical Center Mainz during the first wave of the pandemic from 3 March to 15 May 2020. Our report focuses on the clinical and laboratory abnormalities related to thrombosis and haemostasis. Multiple scientific publications pointing to the high thrombotic risk in COVID-19 [9-13,32], trying to understand its pathophysiology [33-35], suggesting the prognostic value of haemostatic laboratory parameters $[4,36,37]$ and proposing prophylactic and/or therapeutic measures to improve the outcome have been provided [11,38].

From 65 of the 85 registered COVID-19 patients sufficient laboratory data were available to delineate the frequency and extent of haemostatic abnormalities (Table 1). Nine of the patients died, 3 of 29 with complicated and 6 of 17 with critical disease. No autopsies were performed. The incidence of clinically manifest thromboembolic events was rather low and included three venous TE, one mesenteric arterial infarction and three acute coronary syndromes needing percutaneous coronary intervention (Table 1), which is substantially lower than reported by several authors $[12,13]$. Whereas initially published cohorts from China had not received TE prophylaxis [9], other series of patients had a cumulative incidence of TE events up to about 15-60\% (dependent on COVID-19 severity and length of hospitalisation) despite prophylactic or even higher-than-prophylactic doses of LMWH given [13]. Major bleeding events in patients with or without anticoagulation were generally rare [39].

Routine haemostatic laboratory parameters showed strongly elevated fibrinogen and D-dimer levels, the latter being exceedingly high in those with critical disease (Table 2, Figure 1). Prothrombin times expressed as INR were mildly elevated in critical patients and platelet counts were mostly normal and sometimes subnormal independent of COVID-19 severity. Calculating the DIC score [26] taking into account the highest D-dimer and INR and the lowest fibrinogen and platelet count values showed seven of 65 patients having a score $\geq 5$ signalling overt DIC (Table 3 and Table S3). The course of laboratory parameters in these seven individual patients shows a notable difference of their "DIC pattern" as compared to "typical DIC" associated with bacterial sepsis, obstetric complications and other inflammatory conditions $[40,41]$. Six of our DIC patients showed a mild drop of fibrinogen (but none $<100 \mathrm{mg} / \mathrm{dL}$ ), platelet count fell below $50 / \mathrm{nL}$ in only two, and none of the seven showed any abnormal bleeding tendency. These data resemble observations by other groups [20,37] and new designations for the COVID-19 associated haemostatic disturbances have been proposed, i.e., "COVID-19 associated coagulopathy (CAC)" (18) or "Pulmonary intravascular coagulopathy (PIC)" [42] to stress the discrepancy to "classic DIC" [43]. Experts in this field have discussed the current evidence and suggested that CAC during severe COVD-19 should be considered as a prothrombotic phenotype of DIC [44].

Other investigators have labelled the coagulopathy in COVID-19 as thrombotic microangiopathy (TMA) [30,31,45-48]. Nevertheless, the hallmarks of classic TMA, consumptive thrombocytopenia and microangiopathic haemolysis with erythrocyte fragmentation resulting in schistocytes in the peripheral blood smear [21], have neither been found in any of our 22 patients subjected to detailed investigation for TMA (Table 4) nor in most studies from other investigators [49,50]. Mildly or moderately decreased ADAMTS13 activity (18-48\% of normal in 4 of the 22 patients, the other 18 displaying normal activity $>50 \%$ ) (Table 4) as well as normal [50] or subnormal to normal levels [30,45,49] in several previously described patients clearly ruled out thrombotic thrombocytopenic purpura (TTP), which is characterized by $<10 \%$ (and indeed often $<1 \%$ ) ADAMTS13 activity [51]. Most notable findings in the 22 patients were the highly elevated values of VWF activity and antigen and the increased ratio of VWF:antigen/ADAMTS13 activity (Table 4). Whether this imbalance between high VWF concentrations and low levels of its size-regulating protease in our patients, features that have also been described in patients with severe sepsis or septic shock [23,52], is pathophysiologically relevant in COVID-19 remains questionable, 
especially in the absence of consumptive thrombocytopenia. Henry et al. reported that a decreasing ratio of ADAMTS13:act/ VWF:Ag in 52 COVID-19 patients at presentation to the emergency room was predictive for the development of acute kidney injury and a severe form of COVID-19 [48]. However, the decreased ratio of ADAMTS13:act/VWF:Ag in 12 of 52 patients, which did not correlate with platelet count, was mainly due to high VWF:Ag levels. This may, in turn, primarily reflect an augmented VWF release caused by endothelial injury [48]. It is well possible that the highly elevated FVIII:C levels, paralleling the increased VWF values in COVID-19 $[49,50]$ are equally or more relevant in mediating a prothrombotic effect. The explanation for the consistently and often massively elevated VWF values is likely explained by endothelial activation and damage $[14,17,50]$, the latter caused by direct endothelial invasion by the SARS-CoV-2 $[14,53,54]$. The autopsy study by Ackermann and colleagues comparing the lungs of seven patients who died from COVID-19 with those of seven who died from acute respiratory distress syndrome caused by influenza A infection and 10 age-matched control lungs showed distinctive morphologic vascular features in COVID-19. These findings included severe endothelial injury, widespread alveolar capillary fibrinous microthrombi (9-times more prevalent than in influenza-infected lungs) and marked features of (mainly intussusceptive) angiogenesis with formation of new vessels growing into the lumen of existing vessels [14]. Beigee et al. described diffuse alveolar damage and thrombotic microangiopathies in lung biopsies of 31 patients who had died from COVID-19 [16]. Moreover, other autopsy studies confirmed extensive fibrinous microthrombi in the lungs $[53,55]$ and also in some skin lesions [53], from patients succumbed to severe COVID-19. The latter study demonstrated, in addition, significant microvascular deposition of complement activation products, C5b-9, C4d and mannose binding lectin-associated serine protease 2, in colocalization with SARS-Cov-2, hinting at systemic activation of the alternative and lectin-mediated complement pathways [53]. Thus, these studies provide unequivocal proof of "thrombotic microangiopathy", mainly in the lungs. A study of 50 children with COVID-19 including 18 with a multisystem inflammatory syndrome in children (MIS-C) suggested the presence of TMA in 17 of 19 with complete laboratory evaluation. Many showed evidence of systemic complement activation, i.e., increased sC5b-9 levels [47]. Furthermore, first studies describe the successful use of complement inhibitors in COVID-19 patients [56].

Whether the (almost uniformly) lacking laboratory hallmarks of TMA in our COVID19 patients and those described in other cohorts $[49,50]$ is explained by the predominantly pulmonary microangiopathy in COVID-19 remains to be investigated. While both VWFmediated platelet adhesion and aggregation mainly in the microcirculation of brain, kidney and heart as seen in TTP [51] and fibrin microthrombi located predominantly in the kidney as seen in HUS [21,22], will result in erythrocyte fragmentation in the partially occluded microcirculation with the high blood pressure gradient in the arterial circulation, it may be hypothesized that the "COVID-19-associated thrombotic microangiopathy that is often restricted to the pulmonary microcirculation will not produce schistocytes owing to the much lower blood pressure gradient".

\section{Limitations of the Study}

Our study has several limitations. Due to the retrospective approach, relevant parameters were not monitored throughout the course of COVID-19. In particular, we did not assess markers of complement activation, which may play a pathophysiologic role in the prothrombotic alterations of COVID-19 [53] and inhibition of complement activation may be targeted therapeutically [56]. In addition, several other tests, such as viscoelastic methods to study clot formation and fibrinolysis were not performed in this COVID-19 cohort. Whether these latter methods could be useful to identify the thrombotic risk in individual patients and/or to guide antithrombotic treatment remains to be further investigated [57].

Another limitation is a bias regarding the severity of COVID-19. Mostly severely symptomatic patients presented at our University Medical Center and were admitted 
as inpatients and laboratory data on haemostatic alterations were not available from all patients. Therefore, our observational study is merely hypothesis-generating.

\section{Conclusions}

In sum, our observational data on the haemostaseologic abnormalities in real world adult COVID-19 patients admitted to a single academic centre add results suggesting that the haemostatic alterations in severe COVID-19 are not fully fitting into the established categories of DIC and classic TMA. Further pathophysiologic research is needed to provide clinically useful targets for intervention to improve patient outcome.

Supplementary Materials: The following are available online at https://www.mdpi.com/2077 -0383/10/4/671/s1, Figure S1: Organ damage markers in patients with COVID-19. Table S1.1: Comparison of the 65 patients positive for SARS-CoV-2 included (Table 1), and the 20 excluded for analysis of haemostatic alterations because of lacking laboratory data, Table S1.2: Comparison of patient characteristics between groups of varying COVID-19 severity, Table S2.1: Rates of abnormal laboratory values of 65 patients with COVID-19 and analysed for haemostatic abnormalities, Table S2.2: Comparison of laboratory parameters between groups of COVID-19 severity, Table S3: Detailed laboratory data of the seven COVID-19 patients with overt DIC (DIC score $\geq 5$ ). + Patients who died from COVID-19 during hospitalization.

Author Contributions: Conceptualization, T.F. and M.F.S.; methodology, P.M. and T.F.; clinical data acquisition and patient management, P.M., J.G., S.G., A.W., and V.S.; laboratory data analysis, H.R., N.A.W.L., and S.D.; statistical analysis, A.S.; formal analysis, T.F. and M.F.S.; writing—original draft preparation, T.F., M.F.S., and B.L.; writing—review and editing, H.R., S.D., P.R.G., K.J.L., I.S., and B.L. All authors have read and agreed to the published version of the manuscript.

Funding: This research received no external funding.

Institutional Review Board Statement: The retrospective study was approved by German law [Landeskrankenhausgesetz §36 and §37] and by the local Ethics Committee of "Landesärztekammer Rheinland-Pfalz" (reference number: 2020-14988_2) in accordance with the Declaration of Helsinki.

Informed Consent Statement: Patient consent was waived for the retrospective analysis.

Data Availability Statement: The data presented in this study are available on request from the corresponding author. The data are not publicly available due to ethical and privacy restrictions.

Acknowledgments: We would like to thank our colleagues for source data acquisition during the daily work routine. We thank all patients for their support and participation at this project. This manuscript contains data from the medical theses of Philipp Menge, Jan Geotje and Stefan Groenwoldt.

Conflicts of Interest: The authors state that they have no conflict of interest with this publication. Inge Scharrer is a member of the Data Safety Monitoring Board of the BAXALTA 281102 and the SHIRE SHP655-201 study (now both run by TAKEDA), investigating recombinant ADAMTS13 in hereditary and acquired TTP, respectively. Bernhard Lämmle is chairman of the Data Safety Monitoring Committee of the BAXALTA 281102 and the SHP655201 studies (now both run by TAKEDA), investigating recombinant ADAMTS13 in congenital and acquired TTP, respectively. He is on the Advisory Board of Sanofi for Caplacizumab, and received travel and accommodation support for participating at scientific meetings and/or lecture fees from Ablynx, Alexion, Siemens, Bayer, Roche, and Sanofi.

\section{References}

1. Chen, N.; Zhou, M.; Dong, X.; Qu, J.; Gong, F.; Han, Y.; Qiu, Y.; Wang, J.; Liu, Y.; Wei, Y.; et al. Epidemiological and Clinical Characteristics of 99 Cases of 2019-Novel Coronavirus (2019-nCoV) Pneumonia in Wuhan, China. SSRN Electron. J. 2020, 395, 10223. [CrossRef]

2. Guan, W.J.; Ni, Z.Y.; Hu, Y.; Liang, W.H.; Ou, C.Q.; He, J.X.; Liu, L.; Shan, H.; Lei, C.L.; Hui, D.S.C.; et al. Clinical Characteristics of Coronavirus Disease 2019 in China. N. Engl. J. Med. 2020, 382, 1708-1720. [CrossRef]

3. Huang, C.; Wang, Y.; Li, X.; Ren, L.; Zhao, J.; Hu, Y. Clinical features of patients infected with 2019 novel coronavirus in Wuhan, China. Lancet 2020, 395, 497-506. [CrossRef]

4. Tang, N.; Li, D.; Wang, X.; Sun, Z. Abnormal coagulation parameters are associated with poor prognosis in patients with novel coronavirus pneumonia. J. Thromb. Haemost. 2020, 18, 844-847. [CrossRef] 
5. Yang, X.; Yang, Q.; Wang, Y.; Wu, Y.; Xu, J.; Yu, Y.; Shang, Y. Thrombocytopenia and its association with mortality in patients with COVID-19. J. Thromb. Haemost. 2020, 18, 1469-1472. [CrossRef] [PubMed]

6. Ranucci, M.; Ballotta, A.; Di Dedda, U.; Bayshnikova, E.; Poli, M.D.; Resta, M.; Falco, M.; Albano, G.; Menicanti, L. The procoagulant pattern of patients with COVID-19 acute respiratory distress syndrome. J. Thromb. Haemost. 2020, 18, 1747-1751. [CrossRef] [PubMed]

7. Zhang, L.; Yan, X.; Fan, Q.; Liu, H.; Liu, X.; Liu, Z.; Zhang, Z. D-dimer levels on admission to predict in-hospital mortality in patients with Covid-19. J. Thromb Haemost. 2020, 18, 1324-1329. [CrossRef]

8. Favaloro, E.J.; Lippi, G. Recommendations for Minimal Laboratory Testing Panels in Patients with COVID-19: Potential for Prognostic Monitoring. Semin. Thromb. Hemost. 2020, 46, 379-382. [CrossRef] [PubMed]

9. Cui, S.; Chen, S.; Li, X.; Liu, S.; Wang, F. Prevalence of venous thromboembolism in patients with severe novel coronavirus pneumonia. J. Thromb. Haemost. 2020, 18, 1421-1424. [CrossRef]

10. Klok, F.A.; Kruip, M.; Van Der Meer, N.; Arbous, M.; Gommers, D.; Kant, K.; Kaptein, F.; Van Paassen, J.; Stals, M.; Huisman, M.; et al. Confirmation of the high cumulative incidence of thrombotic complications in critically ill ICU patients with COVID-19: An updated analysis. Thromb. Res. 2020, 191, 148-150. [CrossRef]

11. Lodigiani, C.; Iapichino, G.; Carenzo, L.; Cecconi, M.; Ferrazzi, P.; Sebastian, T.; Kucher, N.; Studt, J.-D.; Sacco, C.; Bertuzzi, A.; et al. Venous and arterial thromboembolic complications in COVID-19 patients admitted to an academic hospital in Milan, Italy. Thromb. Res. 2020, 191, 9-14. [CrossRef] [PubMed]

12. Llitjos, J.-F.; Leclerc, M.; Chochois, C.; Monsallier, J.-M.; Ramakers, M.; Auvray, M.; Merouani, K. High incidence of venous thromboembolic events in anticoagulated severe COVID-19 patients. J. Thromb. Haemost. 2020, 18, 1743-1746. [CrossRef] [PubMed]

13. Hasan, S.S.; Radford, S.; Kow, C.S.; Zaidi, S.T.R. Venous thromboembolism in critically ill COVID-19 patients receiving prophylactic or therapeutic anticoagulation: A systematic review and meta-analysis. J. Thromb. Thrombolysis 2020, 50, 814-821. [CrossRef] [PubMed]

14. Ackermann, M.; Verleden, S.E.; Kuehnel, M.; Haverich, A.; Welte, T.; Laenger, F.; Vanstapel, A.; Werlein, C.; Stark, H.; Tzankov, A.; et al. Pulmonary Vascular Endothelialitis, Thrombosis, and Angiogenesis in Covid-19. N. Engl. J. Med. 2020, 383, 120-128. [CrossRef]

15. Wichmann, D.; Sperhake, J.-P.; Lütgehetmann, M.; Steurer, S.; Edler, C.; Heinemann, A.; Heinrich, F.; Mushumba, H.; Kniep, I.; Schröder, A.S.; et al. Autopsy Findings and Venous Thromboembolism in Patients With COVID-19: A prospective cohort study. Ann. Intern. Med. 2020, 173, 268-277. [CrossRef]

16. Sadegh Beigee, F.; Pourabdollah Toutkaboni, M.; Khalili, N.; Nadji, S.A.; Dorudinia, A.; Rezaei, M.; Askari, E.; Farzanegan, B.; Marjani, M.; Rafiezadeh, A. Diffuse alveolar damage and thrombotic microangiopathy are the main histopathological findings in lung tissue biopsy samples of COVID-19 patients. Pathol Res. Pr. 2020, 216, 153228. [CrossRef]

17. Escher, R.; Breakey, N.; Lammle, B. Severe COVID-19 infection associated with endothelial activation. Thromb Res. 2020, 190, 62. [CrossRef]

18. Connors, J.M.; Levy, J.H. COVID-19 and its implications for thrombosis and anticoagulation. Blood 2020, 135, 2033-2040. [CrossRef]

19. Makatsariya, A.D.; Slukhanchuk, E.V.; Bitsadze, V.O.; Khizroeva, J.K.; Tretyakova, M.V.; Tsibizova, V.I.; Elalamy, I.; Gris, J.-C.; Grandone, E.; Makatsariya, N.A.; et al. Thrombotic microangiopathy, DIC-syndrome and COVID-19: Link with pregnancy prothrombotic state. J. Matern. Neonatal Med. 2020, 2020, 1-9. [CrossRef]

20. Levi, M.; Thachil, J. Coronavirus Disease 2019 Coagulopathy: Disseminated Intravascular Coagulation and Thrombotic Microangiopathy_Either, Neither, or Both. Semin. Thromb. Hemost. 2020, 46, 781-784. [CrossRef]

21. Scully, M.; Cataland, S.; Coppo, P.; De La Rubia, J.; Friedman, K.D.; Hovinga, J.A.K.; Lämmle, B.; Matsumoto, M.; Pavenski, K.; Sadler, E.; et al. Consensus on the standardization of terminology in thrombotic thrombocytopenic purpura and related thrombotic microangiopathies. J. Thromb. Haemost. 2017, 15, 312-322. [CrossRef]

22. George, J.N.; Nester, C.M. Syndromes of thrombotic microangiopathy. N. Engl. J. Med. 2014, 371, 654-666. [CrossRef]

23. Kremer Hovinga, J.A.; Zeerleder, S.; Kessler, P.; Romani de Wit, T.; van Mourik, J.A.; Hack, C.E.; ten Cate, H.; Reitsma, P.H.; Wuillemin, W.A.; Lämmle, B. ADAMTS-13, von Willebrand factor and related parameters in severe sepsis and septic shock. J. Thromb. Haemost. 2007, 5, 2284-2290. [CrossRef]

24. Lassnigg, A.; Schmid, E.R.; Hiesmayr, M.; Falk, C.; Druml, W.; Bauer, P.; Schmidlin, D. Impact of minimal increases in serum creatinine on outcome in patients after cardiothoracic surgery: Do we have to revise current definitions of acute renal failure? Crit. Care Med. 2008, 36, 1129-1137. [CrossRef]

25. Mehta, R.L.; Kellum, J.A.; Shah, S.V.; A Molitoris, B.; Ronco, C.; Warnock, D.G.; Levin, A. Acute Kidney Injury Network: Report of an initiative to improve outcomes in acute kidney injury. Crit. Care 2007, 11, R31. [CrossRef]

26. Taylor, F.B.; Toh, C.H.; Hoots, W.K.; Wada, H.; Levi, M. Towards definition, clinical and laboratory criteria, and a scoring system for disseminated intravascular coagulation. Thromb. Haemost. 2001, 86, 1327-1330. [CrossRef]

27. Kokame, K.; Nobe, Y.; Kokubo, Y.; Okayama, A.; Miyata, T. FRETS-VWF73, a first fluorogenic substrate for ADAMTS13 assay. Br. J. Haematol. 2005, 129, 93-100. [CrossRef] [PubMed]

28. Kremer Hovinga, J.A.; Mottini, M.; Lammle, B. Measurement of ADAMTS-13 activity in plasma by the FRETS-VWF73 assay: Comparison with other assay methods. J. Thromb. Haemost. 2006, 4, 1146-1148. [CrossRef] [PubMed] 
29. Levi, M.; Thachil, J.; Iba, T.; Levy, J.H. Coagulation abnormalities and thrombosis in patients with COVID-19. Lancet Haematol. 2020, 7, e438-e440. [CrossRef]

30. Jhaveri, K.D.; Meir, L.R.; Chang, B.S.F.; Parikh, R.; Wanchoo, R.; Barilla-LaBarca, M.L.; Bijol, V.; Hajizadeh, N. Thrombotic microangiopathy in a patient with COVID-19. Kidney Int. 2020, 98, 509-512. [CrossRef]

31. Sweeney, J.M.; Barouqa, M.; Krause, G.J.; Gonzalez-Lugo, J.D.; Rahman, S.; Gil, M.R. Evidence for secondary thrombotic microangiopathy in COVID-19. medRxiv 2020. [CrossRef]

32. Iba, T.; Levy, J.H.; Connors, J.M.; Warkentin, T.E.; Thachil, J.; Levi, M. The unique characteristics of COVID-19 coagulopathy. Crit. Care 2020, 24, 1-8. [CrossRef]

33. Levi, M.; Hunt, B.J. Thrombosis and coagulopathy in COVID-19: An illustrated review. Res. Pr. Thromb. Haemost. 2020, 4, 744-751. [CrossRef]

34. Kusadasi, N.; Sikma, M.; Huisman, A.; Westerink, J.; Maas, C.; Schutgens, R. A Pathophysiological Perspective on the SARS-CoV-2 Coagulopathy. Hemasphere 2020, 4, e457. [CrossRef]

35. Iba, T.; Connors, J.M.; Levy, J.H. The coagulopathy, endotheliopathy, and vasculitis of COVID-19. Inflamm. Res. 2020, 69, 1181-1189. [CrossRef]

36. Lippi, G.; Favaloro, E.J. D-dimer is Associated with Severity of Coronavirus Disease 2019: A Pooled Analysis. Thromb. Haemost. 2020, 120, 876-878. [CrossRef]

37. Han, H.; Yang, L.; Liu, R.; Liu, F.; Wu, K.L.; Li, J.; Liu, X.; Zhu, C. Prominent changes in blood coagulation of patients with SARS-CoV-2 infection. Clin Chem Lab. Med. 2020, 58, 1116-1120. [CrossRef] [PubMed]

38. Terpos, E.; Ntanasis-Stathopoulos, I.; Elalamy, I.; Kastritis, E.; Sergentanis, T.N.; Politou, M.; Psaltopoulou, T.; Gerotziafas, G.; Dimopoulos, M.-A. Hematological findings and complications of COVID-19. Am. J. Hematol. 2020, 95, 834-847. [CrossRef] [PubMed]

39. Al-Samkari, H.; Karp Leaf, R.S.; Dzik, W.H.; Carlson, J.C.; Fogerty, A.E.; Waheed, A.; Goodarzi, K.; Bendapudi, P.K.; Bornikova, L.; Gupta, S.; et al. COVID and Coagulation: Bleeding and Thrombotic Manifestations of SARS-CoV2 Infection. Blood 2020, 136, 486-500. [CrossRef] [PubMed]

40. Gando, S.; Levi, M.; Toh, C.H. Disseminated intravascular coagulation. Nat. Rev. Dis Primers 2016, 2, 16037. [CrossRef]

41. Iba, T.; Levy, J.H.; Wada, H.; Thachil, J.; Warkentin, T.E.; Levi, M.; The Subcommittee on Disseminated Intravascular Coagulation. Differential diagnoses for sepsis-induced disseminated intravascular coagulation: Communication from the SSC of the ISTH. J. Thromb. Haemost. 2019, 17, 415-419. [CrossRef]

42. Fogarty, H.; Townsend, L.; Ni Cheallaigh, C.; Bergin, C.; Martin-Loeches, I.; Browne, P.; Bacon, C.L.; Gaule, R.; Gillett, A.; Byrne, M.; et al. COVID19 coagulopathy in Caucasian patients. Br. J. Haematol. 2020, 189, 1044-1049. [CrossRef]

43. Langer, F.; Kluge, S.; Klamroth, R.; Oldenburg, J. Coagulopathy in COVID-19 and Its Implication for Safe and Efficacious Thromboprophylaxis. Hämostaseologie 2020, 40, 264-269. [CrossRef] [PubMed]

44. Iba, T.; Warkentin, T.E.; Thachil, J.; Levi, M.; Levy, J.H. Proposal of the Definition for COVID-19-Associated Coagulopathy. J. Clin. Med. 2021, 10, 191. [CrossRef] [PubMed]

45. Martinelli, N.; Montagnana, M.; Pizzolo, F.; Friso, S.; Salvagno, G.L.; Forni, G.L.; Gianesin, B.; Morandi, M.; Lunardi, C.; Lippi, G.; et al. A relative ADAMTS13 deficiency supports the presence of a secondary microangiopathy in COVID 19. Thromb. Res. 2020, 193, 170-172. [CrossRef] [PubMed]

46. Airoldi, A.; Perricone, G.; De Nicola, S.; Molisano, C.; Tarsia, P.; Belli, L. COVID-19-related thrombotic microangiopathy in a cirrhotic patient. Dig. Liver Dis. 2020, 52, 946. [CrossRef] [PubMed]

47. Diorio, C.; McNerney, K.O.; Lambert, M.; Paessler, M.; Anderson, E.M.; Henrickson, S.E. Evidence of thrombotic microangiopathy in children with SARS-CoV-2 across the spectrum of clinical presentations. Blood Adv. 2020, 4, 6051-6063. [CrossRef] [PubMed]

48. Henry, B.M.; Benoit, S.W.; de Oliveira, M.H.S.; Lippi, G.; Favaloro, E.J.; Benoit, J.L. ADAMTS13 activity to von Willebrand factor antigen ratio predicts acute kidney injury in patients with COVID-19: Evidence of SARS-CoV-2 induced secondary thrombotic microangiopathy. Int J. Lab. Hematol. 2020. [CrossRef]

49. Huisman, A.; Beun, R.; Sikma, M.; Westerink, J.; Kusadasi, N. Involvement of ADAMTS13 and von Willebrand factor in thromboembolic events in patients infected with SARS-CoV-2. Int J. Lab. Hematol. 2020. [CrossRef] [PubMed]

50. Escher, R.; Breakey, N.; Lämmle, B. ADAMTS13 activity, von Willebrand factor, factor VIII and D-dimers in COVID-19 inpatients. Thromb. Res. 2020, 192, 174-175. [CrossRef] [PubMed]

51. Kremer Hovinga, J.A.; Coppo, P.; Lammle, B.; Moake, J.L.; Miyata, T.; Vanhoorelbeke, K. Thrombotic thrombocytopenic purpura. Nat. Rev. Dis. Primers 2017, 3, 17020. [CrossRef]

52. Levi, M.; Scully, M.; Singer, M. The role of ADAMTS-13 in the coagulopathy of sepsis. J. Thromb. Haemost. 2018, 16, 646-651. [CrossRef]

53. Magro, C.; Mulvey, J.J.; Berlin, D.; Nuovo, G.; Salvatore, S.; Harp, J.; Baxter-Stoltzfus, A.; Laurence, J. Complement associated microvascular injury and thrombosis in the pathogenesis of severe COVID-19 infection: A report of five cases. Transl. Res. 2020, 220, 1-13. [CrossRef]

54. Varga, Z.; Flammer, A.J.; Steiger, P.; Haberecker, M.; Andermatt, R.; Zinkernagel, A.S.; Mehra, M.R.; Schuepbach, R.A.; Ruschitzka, F.; Moch, H. Endothelial cell infection and endotheliitis in COVID-19. Lancet 2020, 395, 1417-1418. [CrossRef] 
55. Dolhnikoff, M.; Duarte-Neto, A.N.; Monteiro, R.A.D.A.; Da Silva, L.F.F.; De Oliveira, E.P.; Saldiva, P.H.N.; Mauad, T.; Negri, E.M. Pathological evidence of pulmonary thrombotic phenomena in severe COVID-19. J. Thromb. Haemost. 2020, 18, 1517-1519. [CrossRef] [PubMed]

56. Mastellos, D.C.; Da Silva, B.G.P.; Fonseca, B.A.; Fonseca, N.P.; Auxiliadora-Martins, M.; Mastaglio, S.; Ruggeri, A.; Sironi, M.; Radermacher, P.; Chrysanthopoulou, A.; et al. Complement C3 vs C5 inhibition in severe COVID-19: Early clinical findings reveal differential biological efficacy. Clin. Immunol. 2020, 220, 108598. [CrossRef] [PubMed]

57. Slomka, A.; Kowalewski, M.; Żekanowska, E. Haemostasis in coronavirus disease 2019-lesson from viscoelastic methods: A systematic review. Thromb. Haemost. 2021. [CrossRef] 